\title{
DEBATE II
}

| nterveñen:

Carlos Aymerich

Antón Baamonde

José Manuel Castelao Bragaña

Xaquín Fernández Leiceaga

Anxo Lugilde

Carlos Navarro

Xosé Luís Rodríguez Pardo 
Carlos Aymerich: Quixera introducir unha cuestión moi específica relacionada coa regulación da campaña electoral no exterior e, sobre todo, co uso dos medios públicos. Nas propostas que ten feito o BNG, tamén se fala do uso de locais no exterior. Existe a este respecto una cuestión máis: non habería que regular outros aspectos? Coñécese noutras experiencias electorais comparadas a figura do «axente electoral»? Temos noticia de que se acaban de contratar axentes; representantes de partidos políticos recoñecían que nas eleccións municipais tiñan máis de cen axentes electorais traballando en Bos Aires; entón a miña pregunta é se esta figura está recoñecida ou non e se consideras que habería que regulala ou perseguila.

Xaquín Fernández Leiceaga: Ao fío da comunicación de Anxo, coincido coa maioría das solucións propostas, aínda que preferiría outra abordaxe do asunto. Sei que isto é máis pragmático e realista, pero posiblemente ten máis sentido primeiro discutir quen son os titulares dos dereitos, que dereitos deben exercer e despois como nos organizamos, aínda que no conxunto das solucións me parece todo bastante sensato. Quixera facer dúas observacións e algunha proposta. Ao da circunscrición no exterior véxolle a vantaxe de completar o dereito de representación dándolle un peso específico nas Cortes Xerais. Ata o de agora vimos que soamente nalgunhas ocasións os residentes no exterior influían, pero a partir dese momento van influír sempre, porque teñen xa os seus escanos. Con isto póñense de manifesto con moita máis agudeza novas necesidades que van máis aló das de garantir o exercicio de dereito ao voto, en condicións semellantes ás que se exercen hoxe en España. Considero que existe un sistema mixto pivotando sobre os consulados e faise necesario que alí onde existan consulados a unha distancia razoable incluso se recorra aos desprazamentos de funcionarios a cidades próximas, e recoller anticipadamente o voto durante o período previo ao día das eleccións en Galicia. Isto precisa dun complemento: o voto por correo con garantías, que si se pode facer. Deste xeito podería levarse a cabo e coido que sería unha boa medida alí onde non existen consulados a disposición.

En calquera caso penso que é posible unha representación no Senado coas funcións que lle son propias, e que non se conseguen cunha circunscrición especial para os residentes no exterior, e en cambio manter no Congreso o seu vínculo co territorio de orixe. Por unha razón, no caso español temos un sistema en que hai comunidades autónomas que son suxeitos políticos. Existen comunidades políticas específicas e, aínda que non se queira, a creación dunha circunscrición no exterior anula esta determinación e provoca que o único vínculo sexa con España no seu conxunto. Presentar esta cuestión dende Galicia ten consecuencias negativas. Por isto eu son partidario de facilitar unha representación específica no Senado, mantela no Congreso e no caso das eleccións autonómicas, se determinamos con firmeza quen ten dereito a exercer o voto, non existirían problemas á hora de manter un sistema como o actual con maiores garantías para o seu exercicio. Isto deberá regularse con urxencia.

Antón Baamonde (Profesor de Filosofía): Quixera presentar unha cuestión que considero central neste asunto e que está referida a quen ten dereito a voto. De xeito comparado, ata que xeracións nos diferentes países teñen dereito a representación?

Xosé Luís Rodríguez Pardo (PSOE): Gustaríame sinalar que existen cuestións que proceden de atrás. Deberiamos citar nesta dirección o acordo adoptado no VIII Pleno do Consello Xeral de Emigración de España, en Torremolinos (Málaga), en 1997. O acordo xeral do pleno do Consello Xeral no apartado de dereitos civís e participación sinala que «o Consello Xeral de Emigración reitera o resolto nos plenos I, II, III, IV, V e VI, respecto da 
modificación da Lei orgánica do réxime electoral xeral -LOREG- que permita a participación electoral dos españois residentes no exterior, número que se incrementou moito coa inscrición de oficio no CERA [...]», para estes efectos contemplarase o exercicio de voto en mesas electorais constituídas nas embaixadas e nos consulados. Podemos apreciar que este asunto xa era abordado en 1997. Polo de agora aínda non se concretou isto. Debemos considerar un sistema de votación informatizada, que existe en países coma Brasil -que se presentara en Caracas no ano 2000 como se realizaba a votación informatizada nas urnas-; isto tería unha consecuencia: eliminaría as posibilidades de manipulación.

Existe ademais, como xa se sinalou, o problema das circunscricións. Realmente constitúe un grave problema que haberá que afrontar, pero é necesario tomar consciencia de que esixe unha modificación da Constitución. Esta soamente establece dous tipos de circunscricións territoriais: provincia e os senadores designados polas asembleas parlamentarias. Nestes casos considéranse incluídos no número do total de habitantes da comunidade autónoma, pero non se sinala un número fixo de senadores por provincia. Como, en calquera caso, tampouco se leva adiante o mandato constitucional de que o Senado é a Cámara de representación territorial, do mesmo xeito, o Senado podería nomear senadores pola circunscrición designada ao emigrante.

Anxo Lugilde: Respecto da cuestión formulada por Carlos Aymerich sobre a regulación dos locais reservados para as campañas, teño que sinalar que estou totalmente de acordo. En calquera caso existe un instrumento como é a televisión española, ademais dos partidos galegos organizados no exterior, os cales poderían facer uso dos locais do mesmo xeito que se utilizan locais municipais e escolas para celebrar mitins no territorio galego.

En relación á cuestión formulada por Xaquín Fernández Leiceaga sobre a necesidade de estudar primeiramente a titularidade, quixera sinalar que se isto se fixese ex novo eu manifestaríame a favor. En todo caso, respecto a esta cuestión hai que resolver, na medida en que se poida, un problema moi grave de enfrontamento entre galegos do interior e do exterior, así como o problema da lexitimidade democrática. Existe unha lei electoral que se pode modificar, concretamente 0 artigo $75^{\circ}$ relativo ao voto por correspondencia, para que se vote de forma presencial, persoal, en urna electrónica ou a través dos consulados; pero a Constitución consagra o dereito ao voto no Congreso, consagra que a circunscrición electoral en España é a provincial, o Estatuto de autonomía de Galicia concédelle o dereito aos galegos residentes no estranxeiro... Considero que existen unha serie de restricións legais, e tendo en conta que falta pouco máis dun ano para as eleccións galegas, no caso de que non se adianten, se non se leva a cabo de inmediato unha reforma da lei electoral é moi posible que esta non chegue a tempo.

En referencia ao que preguntaba Antón Baamonde, existen casos en que se establecen mecanismos para que as segundas ou terceiras xeracións non voten. Un exemplo disto é Suecia, onde se esixe que nalgún momento se residise no país e deixa fóra segundas e terceiras xeracións. Outro exemplo ben diferente é o italiano, onde o propio cónsul italiano en momentos de saturación e exceso de traballo no consulado, chegou a afirmar que «si se presenta un descendente de Julio César terei que darlle a nacionalidade». Neste país a nacionalidade concédeselle incluso aos bisnetos. O sistema italiano é, non obstante, menos xeneroso que o español porque non permite o voto para as locais, tampouco para as rexionais, canalízase a través dos escanos. No Congreso existe 0 mecanismo da prima de maioría nacional, que significa que quen gaña no territorio italiano ten a maioría automática na Cámara; deste xeito os emigrantes non interveñen á hora de formar as maiorías. Porén, a prima de maioría para o Senado faise por rexións, polo que se poden producir situacións como as que se viviron no 2006, que de certo foi moi estraña. Talvez o caso italiano tamén se acabe por reformar.

Respecto ao que sinalaba Xosé Luís Rodríguez Pardo, desculpe a miña omisión ás peticións do Consello das Comunidades pero efectivamente baixo a presidencia de Rodríguez Pardo e despois da de Castelao Bragaña formulouse esa proposta. Ademais o voto en urna xa era unha das peticións feitas pola propia Federación de Sociedades Galegas de Bos Aires nos anos setenta. Existen cartas dun exiliado valdeorrés en Bos Aires dirixidas a Adolfo Suárez nas que solicita o voto en urna, no ano 1977. A representación demandouse no Congreso da Confedera- 
ción de 1913 e incluso Rafael María de Labra reivindicouna no Senado en 1908. Como podemos apreciar hai moitos precedentes, o importante agora é ver se finalmente se leva a cabo.

Carlos Navarro: En relación aos axentes de campañas en termos xerais cómpre sinalar que as regulacións doutros países aluden aos temas xa abordados: requisitos legais, inscricións, procedemento para votar e a forma de organizar a mesa. Máis alá desas disposicións omítese calquera outra que puidese presentar algunha complexidade. Siléncianse aspectos relativos ás campañas, representantes, fiscais e queixas, os cales son resoltos pola vía da práctica. 0 caso de Arxentina resulta interesante xa que contempla que, en termos da conformación das mesas, se reproduza a mesma mecánica que funciona a nivel nacional. Normalmente a nivel interno, no que atinxe á emisión do voto e sufraxio, existen fiscais e axentes dos partidos políticos. Ademais establécese que deberá tratarse de cidadáns do propio país, a excepción do caso arxentino, onde se contempla que deberá ser un cidadán arxentino residente no país de acollida e que poida acreditarse como o representante ou fiscal ante as mesas, ou ben, de ser o caso que non haxa, poderá ser un cidadán de nacionalidade do país de acollida, sempre e cando se comunique á autoridade electoral.

Por outra parte e en relación a como se resolve a cuestión das primeiras e segundas xeracións, hai que sinalar que existen dúas opcións: a primeira relativa á temporalidade e a segunda á cidadanía múltiple. En todo caso, se existise unha imposibilidade aparente de votar porque se ten dobre nacionalidade, naqueles casos en que non está contemplado descoñezo modelos que dispoñan dun mecanismo para identificar dobres nacionalidades e moito menos que se aplique a tales casos algún tipo de sanción. É dicir, pode acontecer que alguén con dobre nacionalidade, recoñecida polo país de orixe e prohibida polo país de naturalización, vote nas dúas eleccións sen que exista unha pescuda en curso interesada en poñer en evidencia estas situacións.

Respecto á pregunta que anteriormente formulaba Carlos Aymerich, relativa a casos en que os migrantes, tendo en conta o seu lugar de orixe, son cuantificados numericamente dentro das circunscricións en que se divide o país, co fin de acadar un lote de escanos maior, que eu coñeza, en ningún caso se toma isto en conta. Por definición non existen rexistros fiables sobre o lugar de orixe e carecemos de estudos. Se nalgún lugar, a través da estatística, isto podería ser factible, a lexislación non o contempla.

José Manuel Castelao Bragaña (Deputado PP): Se me permiten quixera apuntar unha cuestión relativa ao control da dobre nacionalidade. En Arxentina xa existía dito control; cando alguén era cidadán español e se facía cidadán arxentino, o xuíz que concedía a nacionalidade ou o propio Ministerio comunicábao ao Consulado de España, consecuentemente España dábao de baixa no Consulado.

Anxo Lugilde: Si, efectivamente, a modo de inciso histórico convén sinalar que existiu un caso moi soado: o caso Picallo. Cando foi electo deputado en España iniciouse un grande escándalo dado que se nacionalizara arxentino co fin de presentarse como candidato ao Congreso polo Partido Socialista. Naquel momento non existía a dobre nacionalidade entre España e Arxentina e unha das causas da perda da nacionalidade española era precisamente a de ter adquirido outra nacionalidade. Incluso hai declaracións de Lerroux solicitando que abandone a acta de deputado e correspondencia entre Casares Quiroga e o embaixador abordando este asunto. 